\title{
Guimaras State College Quality Assurance Status: An Evaluation
}

\author{
MONA LIZA H. SOLLANO \\ ORCID No. 0000-0002-7410-4641 \\ monalizasollano@yahoo.com \\ Guimaras State College \\ Guimaras, Philippines
}

\begin{abstract}
In a globalized context, quality assurance is a means to support higher education achieve its goals where standards and procedures are useful when they are able to promote quality within Higher Education Institutions. This study aimed to determine the Guimaras State College Quality Assurance Status for 2015 as basis for performance improvement. This study was conducted at Guimaras State College, Guimaras. A descriptive research design was used in this study utilizing 268 respondents. A research-made questionnaire was employed in gathering the data needed. It was found out that Guimaras State College through the office of Quality Assurance has conducted programs/activities towards quality assurance; the needed facilities and equipment are insufficient. The level of capability of the internal accreditors and auditors in performing their respective tasks is excellent while that of the accreditation task force is above average. The level of performance of the conducted programs/activities towards quality assurance is above average. The institution in the conduct of the different quality assurance related programs and activities have met problems mostly is in the insufficiency of supplies, materials, equipment and limited budget particularly for food; least is on the minimum participation of employees in the conducted programs and activities.
\end{abstract}

Keywords: Quality assurance status, performance evaluation, Guimaras State College, descriptive method, Philippines 


\section{INTRODUCTION}

Higher education occupied for years a restricted - and relatively encapsulated - social position. But today, higher education is seen at the center of what we tend to call the society of knowledge, or the information age. Together with moving to center stage in society, it has moved beyond individual societies, and entered the global arena, knowledge, technological developments, services, people, are moving across national borders, and globalization has become the byword of the times (Lemaitre, n.d.). UNESCO recognizes that globalization is a multiple process with important consequences for higher education (Cf. Education superior en una socieded mundializada, 2004).

The growth of higher education, its diversification into different kinds of institutions, the emergence of new providers and the appearance of a new population of students suddenly made higher education look like an alien culture and turned into a world we could no longer recognize. In a globalized context, quality assurance is a means to support higher education achieve its goals where standard s and procedures are useful only when they are able actively to promote quality within higher education institutions, and help them take responsibility for the services they render.

The Commission on Higher Education (CHED) defines quality as the alignment and consistency of the learning environment with the institution's vision, mission and goals demonstrated by exceptional learning and service outcome and the development of a culture of quality. It also advances the notion of quality assurance as having mechanisms, procedures and processes in place to ensure that the desired quality, however, defined and measured is delivered. It connotes 1.) the existence and documentation of systems and processes in the HEI; 2.) the implementation of these systems/processes; 3 .) the quality outcomes that contribute to program excellence and institutional quality CHED's conceptualization of quality assurance is a higher education reform in context of the global and national demands (Corpus, 2012).

To adapt with the national and global demand, Guimaras State College in its quest for quality as it envisions to be the center of excellent in education and green technology generation has submitted its programs to accreditation, ISO 9001:2008 (Quality Management System) certification, and started the mechanism of the CHED's Institutional Sustainability Assessment where the office of Quality Assurance looks into the sustainability of all these mechanisms as the institution develops the culture of quality, sustainability in the aspect of 
man power's capability to the procedures to meet the quality standards to be attuned to CHED's change of paradigm from the existing parameters of quality to the Outcomes-Based approach.

These are programs designed for the improvement of quality assurance in the institution. However, no basis yet as to how these will be improved. Thus, this study was conducted.

\section{FRAMEWORK}

This study was anchored on the "Quality Trilogy" of Joseph Juran. The quality trilogy is made up of quality planning, quality improvement and quality control. If a quality improvement project is to be successful, then all quality improvement actions must be carefully planned out and controlled. Juran believed there were ten steps to quality improvement. These steps are: an awareness of the opportunities and needs for improvement must be created; improvement goals must be determined; organization is required for reaching the goals; training needs to be provided; initialize projects; monitor progress; recognize performance; report on results; track achievement of improvements; and repeat (Ross, 2009).

The researcher conceptualized that the assessment of the Quality Assurance Status of Guimaras State College in terms of the level of capability of the internal accreditors, internal auditors, accreditation task force, level of performance of the conducted programs and activities towards quality assurance, facilities and equipment used and the problems met in the conduct programs and activities would be the basis of performance improvement of the Office of Quality Assurance. Joseph Juran's Quality Trilogy theory is made up of quality planning, quality improvement, and quality control. It states that "if a quality improvement project is to be successful, then all quality improvement actions must be carefully planned out and controlled."

\section{Research Paradigm}

Independent Variable Dependent Variable

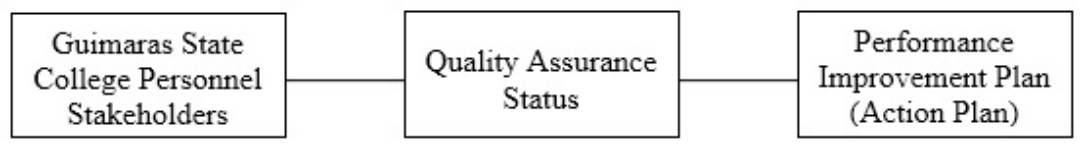

Figure 1. Schematic Diagram of the Study Guimaras State College Quality Assurance Status: An Evaluation 


\section{OBJECTIVES OF THE STUDY}

This study was conducted to determine the Guimaras State College quality Assurance Status as basis for performance improvement for the year 2015. Specifically, it aimed to determine: (1) the level of capability of the internal accreditors, internal auditors and accreditation task force in performing their respective tasks as perceived by the respondents; (2) the level of performance of the conducted programs/activities towards quality assurance; (3) the significant difference in the level of capability of the internal accreditors, internal auditors and accreditation task force in performing their respective tasks as perceived by the respondents; and (4) the problems met in the conduct of the different quality assurance related programs and activities.

\section{METHODOLOGY}

The study was conducted to determine the Guimaras State College Quality Assurance status for the year 2015 as basis for performance improvement of the different programs and activities conducted towards quality assurance.

The descriptive research was used in this study. It is a design that is appropriate for studies which aim to find out what prevail in the present conditions or relationships, held opinions and beliefs, processes and effects, and developing trends (Ardales, 2001).

The respondents of the study were 268 composed of 17 administrators and 251 from faculty, staff and students who were selected through random sampling by lottery using Slovin's formula below:

Formula by Slovin:

Where:

$$
n=\frac{N}{1+N(e)^{2}}
$$

$$
\begin{array}{lll}
n & = & \text { sample size } \\
N & = & \text { total population } \\
e & = & \text { margin of error }
\end{array}
$$


A sample size for every category of respondents like students, faculty and staff was determined using the formula below

Where:

$$
n_{i}=\frac{N_{i}}{N} x n
$$

$$
\begin{array}{lll}
n_{i} & = & \text { sample size to be obtained from a specific SUC } \\
N_{i} & =\quad \text { population size of the specific SUC } \\
N & = & \text { total size of the population } \\
N & = & \text { size sample of the whole sample }
\end{array}
$$

Table 1 presents the data for the distribution of the faculty, staff and student respondents. For the faculty, the respondents were the 41 of the total 111 faculty, for the staff, were the 27 out of the total of 73 and for the students, 184 were the respondents out of the 494 third year and fourth year students at the main campus.

Table 1. Distribution of Respondents

\begin{tabular}{llllll}
\hline \multicolumn{1}{c}{ Category } & & $\mathbf{N}_{\mathbf{i}}$ & $\mathbf{n}_{\mathbf{i}}$ & & $\begin{array}{c}\text { Percent } \\
\mathbf{\%}\end{array}$ \\
\hline Faculty & 111 & & 41 & & 16.33 \\
Staff & 73 & 27 & & 10.76 & \\
Students & 494 & 183 & & 72.91 & \\
\hline \multicolumn{1}{c}{ Total } & 678 & 251 & & 100 & \\
\hline
\end{tabular}

The independent variable in this study was the position of the respondents at Guimaras State College as administrators, faculty, staff, and students and the dependent variable was the Quality Assurance status measured in terms of level of capability of the internal accreditors, internal auditors, and accreditation task force, the level of performance of the conducted programs/activities towards quality assurance, the facilities and equipment used and the problems met in the conduct of quality assurance related programs/activities.

The primary instrument in gathering the data for the research was a researchermade questionnaire where Part I dealt with the level of Capability of Internal Accreditators in the conduct of internal accreditation, Part II dealt with the level of Capability of Internal Auditors in the conduct of internal audit and Part III dealt with the level of capability of the accreditation task force in doing their task during accreditation. In each part the following aspects were evaluated: Professionalism, knowledge/skills and decorum. Part IV was composed of problems probably encountered in the conduct of accreditation and ISO audit. 
The questionnaire was validated by the experts where in general, there was a consensus among the validators on the validity of the questionnaire for the study undertaken.

After the questionnaire was validated, a reliability testing was conducted in the other two campuses, Mosqueda and Baterna to 30 individuals (administrators, faculty, staff and students) exhibiting the same characteristics as the respondents.

Upon retrieval of the accomplished questionnaires, the data were tallied, computer-processed using the Statistical Packages for the Social Science (SPSS) software, tabulated, analyzed, presented and interpreted using the frequency count, percentage, ranking, mean, and ANOVA.

\section{RESULTS AND DISCUSSION}

\section{Level of Capability of Internal Accreditors, Internal Auditors and Accreditation Task Force in Performing their Respective Tasks as Perceived by the Respondents}

\section{Table 2. Level of Capability of Internal Accreditors in the Conduct of Internal Accreditation}

\begin{tabular}{lllc}
\hline \multicolumn{1}{c}{ Categories } & Mean & Sd & Interpretation \\
\hline Professionalism: & & & \\
Discharge duties with integrity and competence & 4.60 & \pm 0.516 & Excellent \\
Perform duties intelligently & 4.50 & \pm 0.527 & Excellent \\
Do work responsibly & 4.00 & \pm 0.816 & Above Average \\
Are competent in handling assigned task & 4.40 & \pm 0.699 & Excellent \\
Complete work promptly and efficiently & 4.30 & \pm 0.823 & Excellent \\
\hline Sub-Mean & 4.36 & \pm 0.631 & Excellent \\
\hline Knowledge/Skills: & & & \\
Have appreciation of the current status of the work involved & 4.50 & \pm 0.707 & Excellent \\
Thorough understand the educational standards being used & 4.50 & \pm 0.850 & Excellent \\
Have sufficient background of the program/area under review & 4.50 & \pm 0.707 & Excellent \\
Are skilled in interviewing, in interpersonal communication & 4.50 & \pm 0.527 & Excellent \\
Write good reports & 4.50 & \pm 0.527 & Excellent \\
\hline Sub-Mean & 4.50 & \pm 0.583 & Excellent \\
\hline Decorum: & & & \\
Maintain cordial relationship with fellow evaluators and the constituents of & 4.40 & \pm 0.516 & Excellent \\
the program/area under evaluation & 4.30 & \pm 0.823 & Excellent \\
Tactful using appropriate language in dealing with anyone & 4.40 & \pm 0.699 & Excellent \\
Manage time very well & 4.30 & \pm 0.823 & Excellent \\
Maintain good grooming and proper decorum & 4.40 & \pm 0.699 & Excellent \\
Discreet in handling sensitive matters & 4.36 & \pm 0.672 & Excellent \\
\hline Sub-Mean & $\mathbf{4 . 4 0}$ & $\pm \mathbf{0 . 5 9 0}$ & Excellent \\
\hline Overall Mean & & &
\end{tabular}

Scale of means: 4.20-5:00 Excellent; 3.40-4.19 Above Average; 2.60-3.39 Average ; $1.80-2.59$ Below Average ; $1.00-1.79$ Poor 
Table 2 shows the level of capability of internal accreditors in the conduct of internal accreditation. Data revealed that for area of professionalism the internal accreditors are excellent with a mean 4.36, \pm 0.631 , for the knowledge/skills capability, the internal accreditors are excellent also with a mean of $4.50, \pm 0.583$ and in the decorum capability, the mean is 4.36, interpreted as excellent and \pm 0.672 . For the level of capability of internal accreditors, the overall mean is $4.40, \pm 0.590$ and interpreted as excellent.

This implies that the internal accreditors are excellent enough to conduct internal accreditation as outcomes of training them through their attendance in AACCUP conferences, trainings/workshops and acting as actual accreditors in other State Universities and Colleges thereby developing their accreditation skills and become excellent accreditors.

\section{Table 3. Level of Capability of Internal Auditors} in the Conduct of Internal Audit

\begin{tabular}{lccc}
\hline \multicolumn{1}{c}{ Capabilities } & Mean & Sd & Interpretation \\
\hline Professionalism: & & & Excellent \\
Discharge duties with integrity and competence & 4.60 & \pm 0.516 & Excellent \\
Perform duties intelligently & 4.50 & \pm 0.527 & Excellent \\
Do work responsibly & 4.00 & \pm 0.816 & Excellent \\
Are competent in handling assigned task & 4.40 & \pm 0.699 & Excellent \\
Complete work promptly and efficiently & 4.30 & \pm 0.823 & Excellent \\
\hline Sub-Mean & 4.36 & \pm 0.631 & Excellent \\
\hline Knowledge/Skills: & & & Excellent \\
Have appreciation of the current status of the work involved & 4.45 & \pm 0.688 & Excellent \\
Thorough understand the educational standards being used & 4.36 & \pm 0.809 & Excellent \\
Have sufficient background of the program/area under review & 4.36 & \pm 0.674 & Excellent \\
Are skilled in interviewing, in interpersonal communication & 4.36 & \pm 0.674 \\
Write good reports & 4.36 & \pm 0.505 & Excellent \\
\hline Sub-Mean & 4.38 & \pm 0.569 & \\
\hline Decorum: & & & Excellent \\
Maintain cordial relationship with fellow evaluators and the constituents of & 4.36 & \pm 0.674 \\
the program/area under evaluation & 4.27 & \pm 0.786 & Excellent \\
Tactful using appropriate language in dealing with anyone & 3.91 & \pm 0.944 & Excellent \\
Manage time very well & 4.55 & \pm 0.688 & Excellent \\
Maintain good grooming and proper decorum & 4.27 & \pm 0.647 & Excellent \\
Discreet in handling sensitive matters & 4.27 & \pm 0.640 & Excellent \\
\hline Sub-Mean & 4.32 & \pm 0.565 & Excellent \\
\hline Overall Mean & &
\end{tabular}

Scale of means: 4.20-5:00 Excellent; 3.40-4.19 Above Average; 2.60-3.39 Average ; $1.80-2.59$ Below Average ; $1.00-1.79$ Poor

Table 3 shows the level of capability of internal auditors in the conduct of internal audit. Data show that for the areas of professionalism, the mean is 4.36, 
\pm 0.631 interpreted as excellent, in the knowledge/skills, the level of capability of internal auditors is excellentas shown in the mean 4.38, \pm 0.569 and for decorum mean is $4.27, \pm 0.640$ interpreted as excellent. The overall mean for the level of capability of internal auditors is $4.32, \pm 0.565$ interpreted as excellent. This means that the internal auditors are excellent in the conduct internal audit as they are well equipped with necessary knowledge and skills through the trainings/ workshops extended to them to be capable in the job assigned to them.

\section{Table 4. Level of Capability of Accreditation Task Force in doing Task during Accreditation}

\begin{tabular}{|c|c|c|c|}
\hline Categories & Mean & $\mathrm{Sd}$ & Interpretation \\
\hline \multicolumn{4}{|l|}{ Professionalism: } \\
\hline Discharge duties with integrity and competence & 4.18 & \pm 0.751 & Above Average \\
\hline Perform duties intelligently & 4.09 & \pm 0.831 & Above Average \\
\hline Do work responsibly & 4.27 & \pm 0.647 & Excellent \\
\hline Are competent in handling assigned task & 3.91 & \pm 0.831 & Above Average \\
\hline Complete work promptly and efficiently & 3.82 & \pm 0.982 & Above Average \\
\hline Sub-Mean & 4.05 & \pm 0.743 & Above Average \\
\hline \multicolumn{4}{|l|}{ Knowledge/Skills: } \\
\hline Have appreciation of the current status of the work involved & 4.09 & \pm 0.831 & Above Average \\
\hline Thorough understand the educational standards being used & 4.18 & \pm 0.874 & Above Average \\
\hline Have sufficient background of the program/area under review & 4.00 & \pm 0.894 & Above Average \\
\hline Are skilled in interviewing, in interpersonal communication & 4.00 & \pm 0.894 & Above Average \\
\hline Write good reports & 4.09 & \pm 0.831 & Above Average \\
\hline Sub-Mean & 4.07 & \pm 0.801 & Above Average \\
\hline \multicolumn{4}{|l|}{ Decorum: } \\
\hline $\begin{array}{l}\text { Maintain cordial relationship with fellow evaluators and the } \\
\text { constituents of the program/area under evaluation }\end{array}$ & 4.27 & \pm 0.786 & Excellent \\
\hline Tactful using appropriate language in dealing with anyone & 4.27 & \pm 0.786 & Excellent \\
\hline Manage time very well & 3.82 & \pm 1.079 & Above Average \\
\hline Maintain good grooming and proper decorum & 4.45 & \pm 0.688 & Excellent \\
\hline Discreet in handling sensitive matters & 4.00 & \pm 0.775 & Above Average \\
\hline Sub- Mean & 4.16 & \pm 0.747 & Above Average \\
\hline Overall Mean & 4.09 & \pm 0.754 & Above Average \\
\hline
\end{tabular}

Scale of means: 4.20-5:00 Excellent; 3.40-4.19 Above Average; 2.60-3.39 Average ; $1.80-2.59$ Below Average ; $1.00-1.79$ Poor

Table 4 shows the level of capability of the accreditations task force in the preparation of documents for the accreditation survey visit. Data revealed that for the category of professionalism, the mean is $4.05, \pm 0.743$ interpreted as above average, in knowledge/skills capability is above average as shown in the mean of $4.07, \pm 0.801$, and for decorum, the level of capability is above average, with mean of $4.16, \pm 0.747$. The overall mean is $4.07, \pm 0.754$ which is interpreted as above average. 
This means that the development of the capability of the accreditation task force is difficult to sustain due to the changing in the member composition particularly the casual faculty members who lack trainings about accreditation but are in the task force.

\section{Difference in the Level of Capability of Internal Accreditors, Internal Auditors and Accreditation Task Force in Performing their Respective Task as Perceived by the Respondents}

Table 5. Difference in the Perception of Respondents on the Level of Capability of Internal Auditors, Internal Accreditors, and Accreditation Task Force

\begin{tabular}{|l|c|c|c|c|c|}
\hline & Sum of Squares & df & Mean Square & F & Sig. \\
\hline Between Groups & 0.797 & 2 & 0.398 & $13.93^{*}$ & .000 \\
Within Groups & 1.201 & 42 & 0.029 & & \\
Total & 1.998 & 44 & & & \\
\hline
\end{tabular}

*p $<.05$ level of significance

Table 5 shows the significant difference in the level of capability of internal accreditors, internal auditors and accreditation task force. Results revealed a significant difference in the level of capability of internal accreditors, internal auditors and accreditation task force in performing their respective tasks as perceived by the respondents as shown in $\mathrm{F}=13.93, \mathrm{P}=.000$. The probability value is less than .05 , hence significant. This means that the level of capability of the internal accreditors, internal auditors and accreditation task force vary.

This implies that internal accreditors, and internal auditors are more capable than the accreditation task force since the composition of the former is not varied unlike that of the accreditation task force. 


\title{
Level of Performance of the Conducted Programs/Activities towards Quality Assurance
}

\author{
Table 6. Level of Performance of the Conducted \\ Programs/Activities towards Quality Assurance
}

\begin{tabular}{|c|c|c|c|}
\hline Categories & Mean & Sd & Interpretation \\
\hline \multicolumn{4}{|l|}{ A. Content } \\
\hline Consistency with the institution's vision, mission and quality policy & 4.45 & \pm 0.640 & Excellent \\
\hline Relevance, significance to quality assurance & 4.33 & \pm 0.629 & Excellent \\
\hline Achievement of objectives & 4.29 & \pm 0.638 & Excellent \\
\hline Sub-Mean & 4.36 & \pm 0.554 & Excellent \\
\hline \multicolumn{4}{|l|}{ B. Management } \\
\hline Time Management & 3.90 & \pm 0.818 & Above Average \\
\hline Organization of the program/activity & 4.15 & \pm 0.764 & Above Average \\
\hline Involvement of participants & 4.02 & \pm 0.766 & Above Average \\
\hline Sub-Mean & 4.02 & \pm 0.686 & Above Average \\
\hline \multicolumn{4}{|l|}{ C. Mean } \\
\hline Appropriateness & 4.19 & \pm 0.766 & Above Average \\
\hline Convenience day and time & 3.98 & \pm 0.716 & Above Average \\
\hline Arrangement of fixture & 4.06 & \pm 0.780 & Above Average \\
\hline Sub- Mean & 4.08 & \pm 0.682 & Above Average \\
\hline \multicolumn{4}{|l|}{ D. Facilities/Equipment } \\
\hline Adequacy & 4.11 & \pm 0.737 & Above Average \\
\hline Effectiveness & 4.12 & \pm 0.776 & Above Average \\
\hline Usefulness & 4.21 & \pm 0.757 & Excellent \\
\hline Sub- Mean & 4.15 & \pm 0.708 & Above Average \\
\hline \multicolumn{4}{|l|}{ E. Foods Served (If applicable) } \\
\hline Quality & 4.12 & \pm 0.732 & Above Average \\
\hline Sufficiency & 4.11 & \pm 0.712 & Above Average \\
\hline Cleanliness & 4.18 & \pm 0.687 & Above Average \\
\hline Sub- Mean & 4.14 & \pm 0.636 & Above Average \\
\hline Overall Mean & 4.15 & \pm 0.567 & Above Average \\
\hline
\end{tabular}

Table 6 shows the level of performance of the conducted programs/activities towards quality assurance like accreditation, ISO audit, awareness/orientation, trainings/workshops. Results revealed that for the content of programs/activities the mean is $4.36, \pm 0.554$ which is interpreted as excellent, in management the level of performance is above average with the mean of 4.02 and \pm 0.686 . For the venue, where the programs/activities are held, the level of performance is above average, with mean 4.08 and \pm 0.682 . As to the aspect of facilities/equipment the mean is $4.15, \pm 0.708$ which is interpreted as above average and for the foods served, the performance is above average with mean $4.15, \pm 0.567$. The overall mean for the level of performance of the conducted programs/activities towards quality assurance is above average. 
This implies that improvement in the aspect of management, venue, facilities/ equipment and foods served is to be considered in the conduct of quality assurance programs/activities.

\section{Problems Met in the Conduct of the Different Quality Assurance Related Programs and Activities}

Guimaras State College in the conduct of the different quality assurance related programs and activities have encountered the following problems: Supplies and Materials, facilities and equipment are insufficient; limited budget particularly for food; delayed procurement on needed supplies and materials ; responses to requested documents from different offices is slow; delayed submission of reports by the internal accreditors/internal auditors; employees are multi-tasked due to insufficiency of capable personnel; insufficient time of preparation; poor attendance of employees in programs and meetings; and employees' participation in the conduct of programs/activities is minimal. In additional, for ISO audit a problem in "lack of internalization of the established quality procedure/policies has been met".

\section{CONCLUSIONS}

Based on the findings of the study, the following conclusions were drawn:

1. The level of capability of the internal accreditors and internal auditors in performing their respective tasks is excellent while that of the accreditation task force is above average. There is significant difference in the level of capability of the internal accreditation, internal auditors and accreditation task force.

2. The level of performance of the conducted programs/activities towards quality assurance is above average.

3. Guimaras State College in the conduct of the different quality assurance related programs and activities have met problems where most is in the insufficiency of supplies, materials, facilities and equipment and limited budget particularly for food and the least is on the minimum participation of employees in the conducted programs and activities. 


\section{LITERATURE CITED}

Bowen, R. (2013). Theories in total quality management (TQM). Retrieved December 9, 2015, form http://www.brighthubpm.com/methodsstartegies/72 443-theories-in-total-quality-management-tqm.

Cf. Educación superior en una sociedad mundializada (2004). UNESCO, Paris

CHED Memorandum Order No. 46, S. (2012). Policy-standard to enhance quality assurance (QA) in Philippines higher education through an outcomes-based and typology-based QA. Retrieved January 5, 2016, from http://www.ched.gov.ph/wp-content/uploads/2013/07/CMONo.46s2012.pdf.

Curpos, M., et al. (2012). Quality assurance: concepts, structures and practices. Accrediting agency of chartered colleges and universities in the Philippines (AACCUP), Inc.

ESG (2015). Standards and guidelines for quality assurance in the european higher education area. Brussels, Belguim: European Association for Quality Assurance in Higher Education (ENQA). Retrieved June 2016, form http://www.eua.be/Libraries/quality-assurance/esg_2015.pdf? sfvrsn $=0$

Government Quality Management System Standards (GQMSS) (2016). Guidance document for the application of ISO 9001:2000 for public sector organization (including among others, State Universities and Colleges). Retrieved January 10, 2016, from http://www.unesco.org/ en/highereducation/themes/quality-assurance-andrecognition

Haug, G. (2013). Quality assurance culture: Cooperation or competition?. Proceedings ICQA 2013 international conference on QA culture: Cooperation or competition. Bangkok, Thailand: The office for nation education standards and quality assessment (Public Organization), pp 23-24. 
ICQA (2014). Booklet on the Full Paper Presentations

INQAAHE (2007). Guidelines of good practices in quality assurance.

International network for quality assurance agencies in higher education. Retrieved June 2016, form http://www.cna.gov.co /1741/articles-186350_Guidelines_INQAAHE.pdf

IQM-HE (2016). Handbook for internal quality management in competencebased higher education. Retrieved October 2016, from http:// www.enqa.eu/indirme/IQM-HE\%20Handbook.pdf

Kahveci, T., et al. (2012). Quality assurance in higher education institutions using strategic information system. International conference on new horizons in education Inte2012. Retrieved October 14, 2015, from http://www.sciencedirect.com/science/article/pii/S1877042812039 523

Kanjanapanyakom, R. (2005). Thai experience with quality assurance. Retrieved June 23, 2016, from fulbrightthai.org/data/articles/exp.doc

Lemaitre, M. (2016). Quality assurance and recognition in a global perspective. Chile: Comision nacional de acreditation. Retrieved January 5, 2016, http://www.aic.lv/bolona/Bologna/Bergen_conf/Parallel-ses/050519_ 3_Lemaitre.pdf

McAleavy, T. (2013). QA as a means to educational improvement. Proceedings ICQA 2013 international conference on QA culture: Cooperation or competition. Bangkok, Thailand: The office for nation education standards and quality assessment (Public Organization), pp 31-40.

IONESQA (2013). Manual for higher education institutions: The third-round or external quality assessment 2011-2015 (3rd ed.). Bangkok, Thailand: The office for nation education standards and quality assessment (Public Organization). 
ONESQA (2014). Proceedings ICQA 2014 international conference on QA QB QC. Bangkok, Thailand: The office for nation education standards and quality assessment (Public Organization). Retrieved January 5, 2016, from http://61.47.34.34/icqa2016/images/downloads/ Proceedings_ICQA2014.pdf

Pijano, C. (2010). Quality assurance and accreditation: The Philippines experience. Retrieved October 2, 2016, from http://www.niad.ac.jp/n_ kokusai/intl_engagement/seminar/12_no17_paascu_slides.pdf

Primer on the Quality Assurance and Institutional Sustainability Assessment of HEIs (2016). Retrieved January 7, 2016, from https://docs.google. $\mathrm{com} /$

Ross, J. (2009). Total quality management. Retrieved January 7, 2016, from https://totalqualitymanagement.wordpress.com/2009/06/07/drjoseph-juran.

Ruiz, A. \& Sabio, C. (2012). Quality assurance in higher education in the Philippines. Asian Journal of Distance Education. vol 10, no. 2, pp 63 70. Retrieved October 20, 2016 , form http://www.asianjde.org/2012 v10.2.Ruiz.pdf

Tumapon, T. (2015). Quality Assurance in higher education. The Manila Times. Retrieved December 10, 2016, from http://www.manilatimes.net/ quality-assurance-in-higher-education/211390 